\title{
New casting glass technique through the use of geopolymers
}

\author{
Jorge Duran-Suarez ${ }^{1, *}$, Maria-Angeles Villegas ${ }^{2}$, Rafael Peralbo-Cano ${ }^{1}$ and Joâo Castro Gomes ${ }^{3}$ \\ ${ }^{1}$ Sculpture Department. University of Granada. 18010. Spain \\ ${ }^{2}$ Instituto de Historia. Spanish National Research Council (CSIC). 28037 Madrid, Spain. \\ ${ }^{3}$ C-MADE. Centre of Materials \& Building Technologies. 6201-001 Covilhã. Portugal.
}

\begin{abstract}
By using silicate inorganic binders and glass waste (colourless or coloured) it is possible to mould technical and artistic elements, which later can be hardened by means of high temperature processing. This procedure is controlled by both the glass transition temperature of binder and of glass waste used as aggregate. "water glass", catalysed with sodium hydroxide was used as a binder of glass shards from common industrial bottles, classified to a grain size distribution below $2 \mathrm{~mm}$. Chemical analysis shows similarity of silica content between binder and aggregates of recycled glass, establishing as main differences in the percentages of chromophore oxides. In addition dilatometry curves of the two materials show close glass transition temperature values $\left(575\right.$ and $598{ }^{\circ} \mathrm{C}$, respectively), fact that facilitates sintering between binder and aggregates. The non-heat-treated samples present good compactness and mechanical resistance values, improved with heat-treatment at $700{ }^{\circ} \mathrm{C}$. The high compactness of heated samples, showing rounded aggregate grains and softening of binder could let a good way for obtaining well-consolidated technical elements, made of recycled glass. From this test, it would be possible to use thermal ranges between 550 and $600{ }^{\circ} \mathrm{C}$, as well as shorter exposure times for a proper hardening.
\end{abstract}

\section{Introduction and objectives}

The restoration of the heritage elements made of glass and the creation of new products manufactured with technical and artistic value is a great technical challenge, as well the use of big quantities of material resources. For this reason it is proposed a review of the traditional methods of restorative intervention and technical production, simplifying the methodological process, a reduction in energy costs and a recyclability of waste materials.

To produce new glasses in these cases have been designed a new compound made of liquid binder (sodium silicate) and ground glass as aggregate from common glass bottles (sodium calcium) colored or not colored. This compound is based on the production of geopolymers [1, 2, 3].

The main objective is to obtain glasses for different applications (restorative, technical and artistic) with a simplification of production processes and a significant reduction of working temperature without reducing quality of the glass products, related to its compactness and low porosity.

\section{Materials and methods}

The starting materials used in this study have been glass aggregates and silicon binder.

1. Shards of glass from common green bottles crushed, whose grain sizes do not exceed $2 \mathrm{~mm}$.
2. Sodium silicate binder (geopolymers) at $75 \%$, catalyzed with sodium hydroxide at $25 \%$.

The preparation of glass mortars was made from a mixture of crushed glass, proportionally to $80 \%$ in volume with a binder to $20 \%$ in volume.

All components were properly mixed and compacted in a polystyrene mould. For binder activating and hardening, samples were cured in oven at $40^{\circ} \mathrm{C}$ for $24 \mathrm{~h}$.

Samples were cut with a small diamond saw. Part of samples were fired up to $700^{\circ} \mathrm{C}$, during twelve hours, provoking a partial melting of the aggregates and consolidated binder. Firing curve is represented in figure 1 .

\section{Analytical techniques used}

1. Macroscopic photography of samples, untreated and treated at high temperature, using camera Canon EOS 5 D-Matk IV, provided with objective macro Canon MPE $65 \mathrm{~mm} \mathrm{f} / 2.81-5 \mathrm{x}$.

2. Chemical analysis (x-ray fluorescence, FRX) of glass aggregates and binder. Was used a sequential spectrometer of dispersive wavelength with $\mathrm{x}$-ray generator of $4 \mathrm{KW}$ (PHILIPS Magix Pro-PW-2440).

3. Characterization of thermal properties of binder and glass aggregates from the study of their dilatometric curves (differential dilatometer Netzsch Gerätebau 402EP model, which measure linear expansion coefficient $\alpha$ and Glass transition temperature ( $\mathrm{Tg})$.

\footnotetext{
* Corresponding author: giorgio@ugr.es
} 
4. Morphological study and elemental analysis of samples (with and without thermal compaction at $700^{\circ}$ C), using Scanning Electron Microscope (SEM) high resolution GEMINI (FESEM) CARL ZEISS (CIC-UGR), equipped with system of Chemist-EDX analysis.

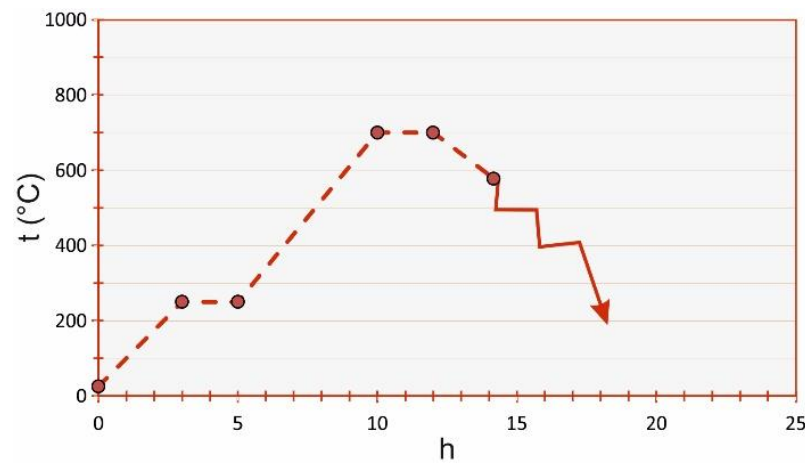

Fig. 1. Thermal curve $(t / h)$ used for compaction of samples at $700{ }^{\circ} \mathrm{C}$ in ceramic kiln.

\section{Results and discussion}

The hardened binder "water glass" that compact aggregates of glass in any of the samples is not visible (40 ${ }^{\circ} \mathrm{C} / 24 \mathrm{~h}-700{ }^{\circ} \mathrm{C} / 12 \mathrm{~h}$ ).

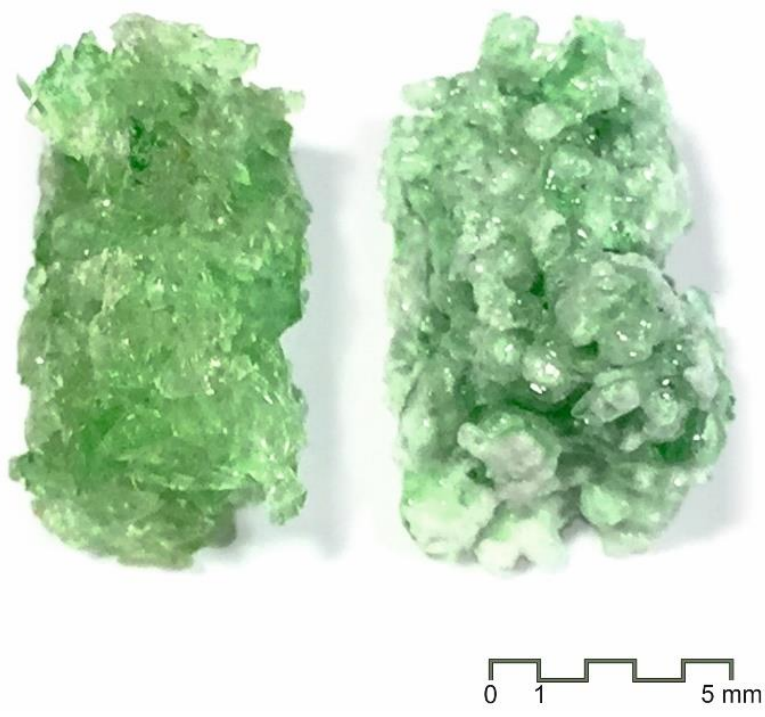

Fig. 2. Macro photography of samples compacted with geopolymers (left), and thermally at $700{ }^{\circ} \mathrm{C}$ (right). Note the rounding of aggregates of glass after heat treatment (right) and its better compaction.

In both cases it is observed that samples compaction is very good, highlighting those thermally treated at $700{ }^{\circ} \mathrm{C}$ having aggregates rounding and partial melting by contact (figure 2).

The chemical analysis shows similarity of silica content between the binder and the aggregates of recycled glass, being the main differences the percentages of chromophore oxides. Both materials have elemental similarity and should not have problems due to chemical incompatibility (table 1 and figure 3).
Table 1. Chemical analysis (wt. \%) obtained by XRF spectrometry of the aggregates and the binder from water glass (ND: not determined).

\begin{tabular}{|c|c|c|}
\hline Oxides & $\begin{array}{c}\text { Green glass } \\
\text { aggregates }\end{array}$ & $\begin{array}{c}\text { Binder made of "water } \\
\text { glass" }\end{array}$ \\
\hline $\mathrm{Al}_{2} \mathrm{O}_{3}$ & 1.92 & 1.06 \\
\hline $\mathrm{CaO}$ & 10.80 & $\mathrm{ND}$ \\
\hline $\mathrm{Fe}_{2} \mathrm{O}_{3}$ & 0.31 & 1.14 \\
\hline $\mathrm{K}_{2} \mathrm{O}$ & 0.95 & $\mathrm{ND}$ \\
\hline $\mathrm{MgO}$ & 0.87 & 76.70 \\
\hline $\mathrm{SiO}_{2}$ & 72.30 & 21.10 \\
\hline $\mathrm{Na}_{2} \mathrm{O}$ & 12.60 & $\mathrm{ND}$ \\
\hline $\mathrm{Cr}_{2} \mathrm{O}_{3}$ & 0.19 & $\mathrm{ND}$ \\
\hline $\mathrm{SrO}$ & 0.03 & \\
\hline
\end{tabular}

In relation to thermal behavior of binder and aggregates, data relating to maximum test temperature, linear expansion coefficient $(\alpha)$ and glass transition temperature $(\mathrm{Tg})$ are very similar (table 2$)$.

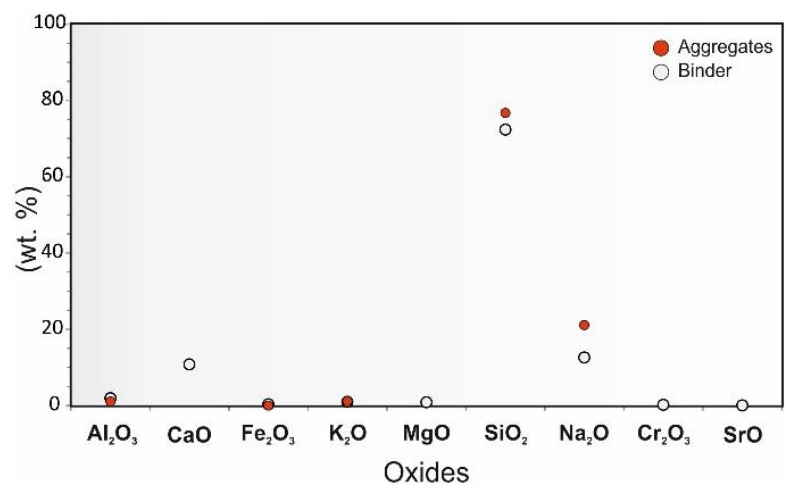

Fig. 3. Chemical analysis (wt. \%) differences between aggregates and binder, starting materials used in this study.

Because of small differences between both starting materials it is posible to infer that manufactured thermal compaction process could be easier and less expensive, and could be conducted with sintering temperatures below $700{ }^{\circ} \mathrm{C}$ (temperature of compaction experienced in our research work).

In addition lower values of linear expansion of binder would facilitate better adherence of aggregates after the compaction thermal process, during the cooling of new manufactured materials [4]. 
Table 2. Thermal parameters of the starting materials obtained from their dilatometric curves.

\begin{tabular}{|c|c|c|}
\hline Parameters & $\begin{array}{c}\text { Green glass } \\
\text { aggregates }\end{array}$ & $\begin{array}{c}\text { Binder made of } \\
\text { "water glass" }\end{array}$ \\
\hline $\begin{array}{c}\text { Maximum test } \\
\text { temperature }\left({ }^{\circ} \mathrm{C}\right)\end{array}$ & 689 & 659 \\
\hline $\begin{array}{c}\text { Linear expansion } \\
\text { coefficient } \\
\alpha\left(\mathrm{x} 10^{-6} \mathrm{~K}^{-1}\right)\end{array}$ & 9,44 & 8,80 \\
\hline $\begin{array}{c}\text { Glass transition } \\
\text { temperature } \\
\mathrm{Tg}_{\mathrm{g}}\left({ }^{\circ} \mathrm{C}\right)\end{array}$ & 575 & 598 \\
\hline
\end{tabular}
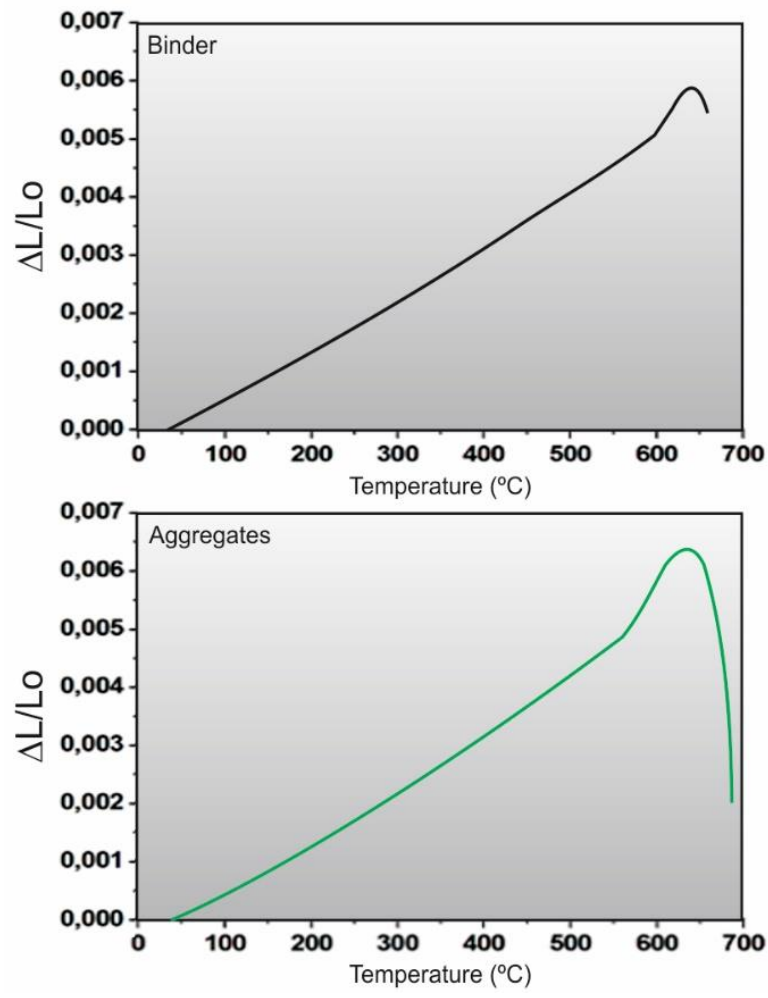

Fig. 4. Dilatometric curves showing thermal behaviour of the binder and the aggregates used in this study (recorded with a differential dilatometer Netzsch Gerätebau).

The results of electron microscopy (SEM) related to the morphology parameters (figures 5 to 10) showing good adherence in samples compacted at low temperature, due to the compacting effect of silicon inorganic polymer (water glass) with glass aggregates. Is the case showed in figure 5, where shards of glass have been colored in green and areas of polymer filling have been highlighted in red color.

Also, water glass binder has hardened properly with the proportion of added sodium catalyst in the mixture, together its activation in an oven at low temperature (40 ${ }^{\circ} \mathrm{C} / 24 \mathrm{~h}$ ). Undetected pores in binder with this curing temperature; aggregates of glass are not rounded, but that their edges are sharp.

Porosity derived from the binder appears on some surfaces of aggregates with form of cross-linked, due to contraction of the binder and the small amount deposited in these areas (figure 6).
Is significant a surface porosity of the binder in certain cases, without this fact determine bad compaction of samples hardened at low temperature.

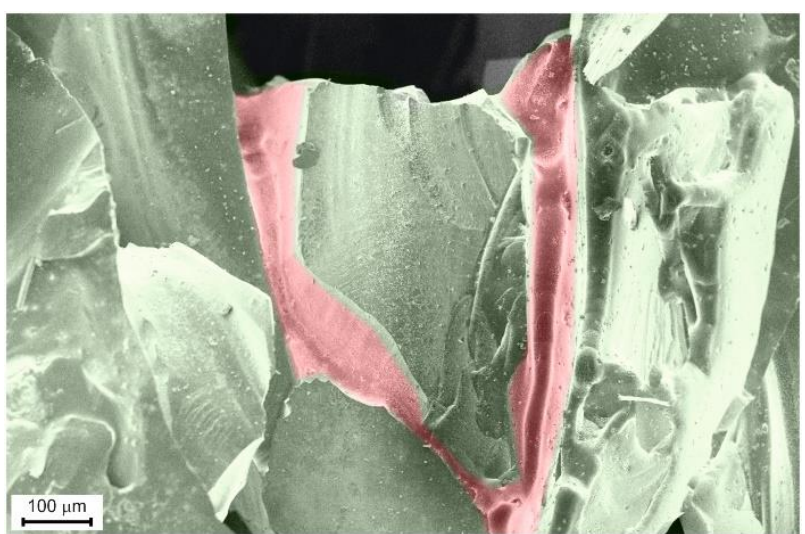

Fig. 5. SEM detail of the "mortar" made of glass aggregates and water glass binder. Note the sharp edges of the aggregates (green). The binder filled the pores and fissures (red color).

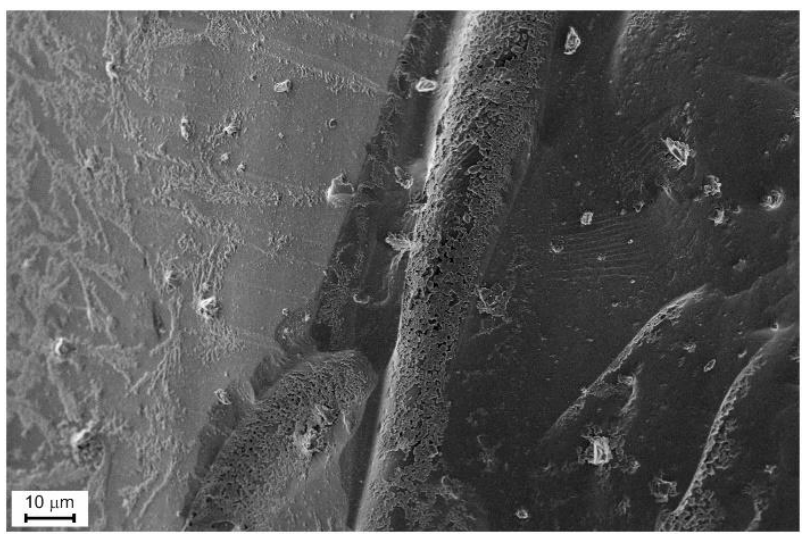

Fig. 6. Detail of glass mortar texture $\left(40{ }^{\circ} \mathrm{C} / 12 \mathrm{~h}\right)$ showing a filling of water glass binder and reticulated surface of the binder in some glass aggregates.

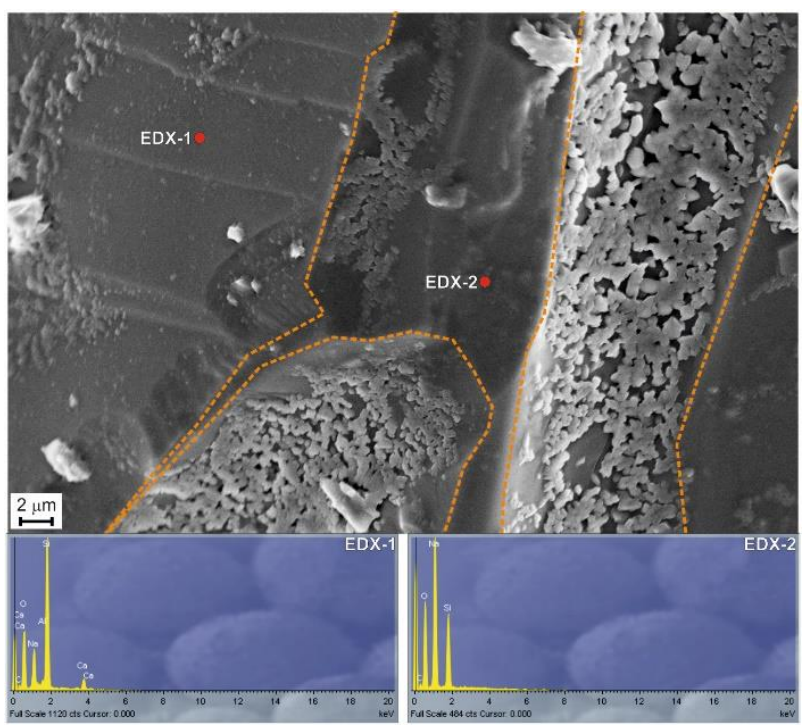

Fig. 7. Detail of sample compacted at $40{ }^{\circ} \mathrm{C} / 24 \mathrm{~h}$, highlighting strong adhesion between binder and aggregates of glass (dotted line in orange color), and secondary porosity in some aggregates edges. Analysis EDX aggregates (EDX-1) and binder (EDX-2).

In relation to EDX analysis of the aggregates and the binder (figure 7), glass aggregates have a majority 
proportion of $\mathrm{Si}$ and minor presence of $\mathrm{Ca}$ and $\mathrm{Na}$, according to FRX analysis.

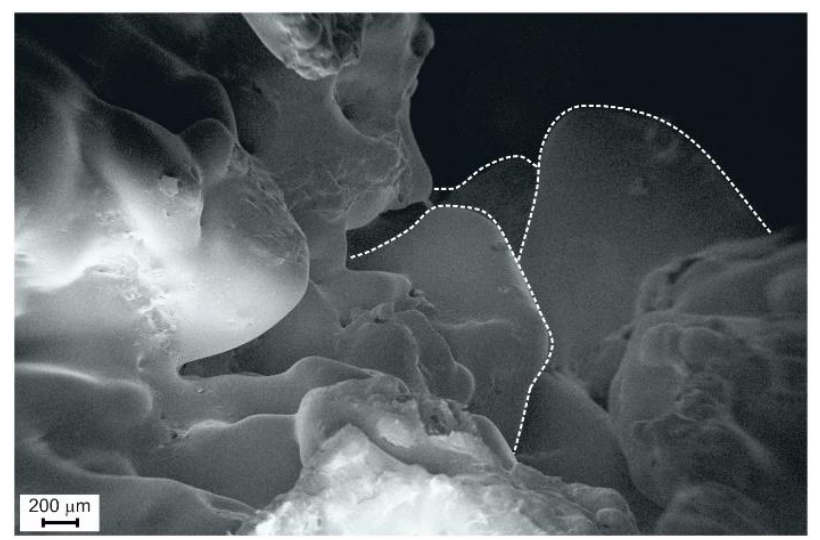

Fig. 8. Detail of sample compacted at $700{ }^{\circ} \mathrm{C} / 12 \mathrm{~h}$. Rounded grains (dotted line in white color) partially melted are highlighted. Water glass binder is also melted, filling pores and cracks.

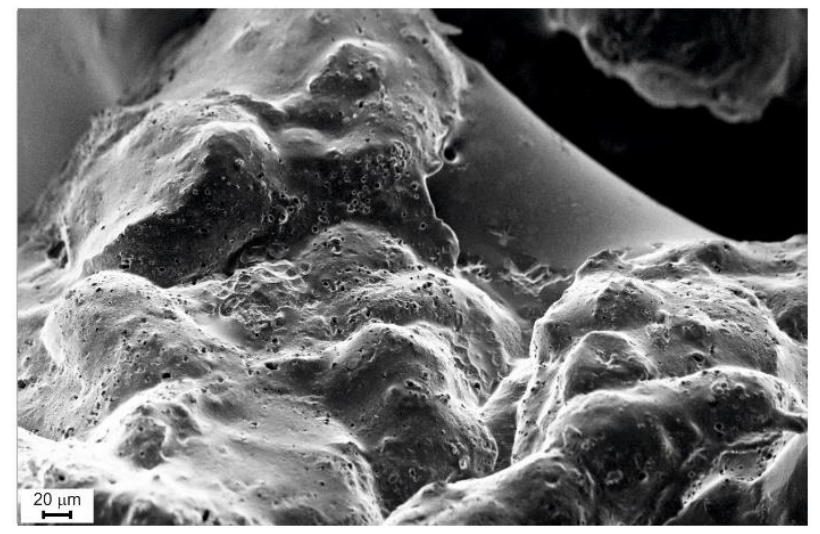

Fig. 9. Detail of sample compacted at $700{ }^{\circ} \mathrm{C} / 12 \mathrm{~h}$. The partial melting of aggregates and the binder is remarkable.

In addition, the samples treated to thermal compaction $\left(700^{\circ} \mathrm{C} / 12 \mathrm{~h}\right)$ present clearly their aggregates rounded and partial melting of binder, due to high temperature during essay. All these effects improve compactness between different elements (figure 8).

It is remarkable with this thermal treatment $\left(700{ }^{\circ} \mathrm{C} / 12\right.$ h) that volumetric variation of the samples is not high, although excellent compaction can be observed.

Due to the texture of the binder, it can be inferred that compaction treatment had higher temperature of the needed (figure 9), as some de-vitrification cores appear in glass aggregates as a side effect. In addition superficial bubbles together with "boiling effect" of water glass binder allow us to confirm excess temperature in the essay developed.

The image of figure 10 shows a perfect adhesion between binder (water glass) and glass aggregates, as well as cited de-vitrification cores in glass aggregates. EDX analysis of the binder and aggregates correspond to those measured in samples compacted without high temperature (figure 10).

\section{Conclusions}

The design of products manufactured with fragments of glass, from glass recycling, and siliceous inorganic binders (water glass) is an excellent alternative in the industrial, technical and artistic production as sustainability concept. On the other hand the application of these products in specific fiels like architecture, decoration and heritage restoration implies great advantages for saving energy and materials.

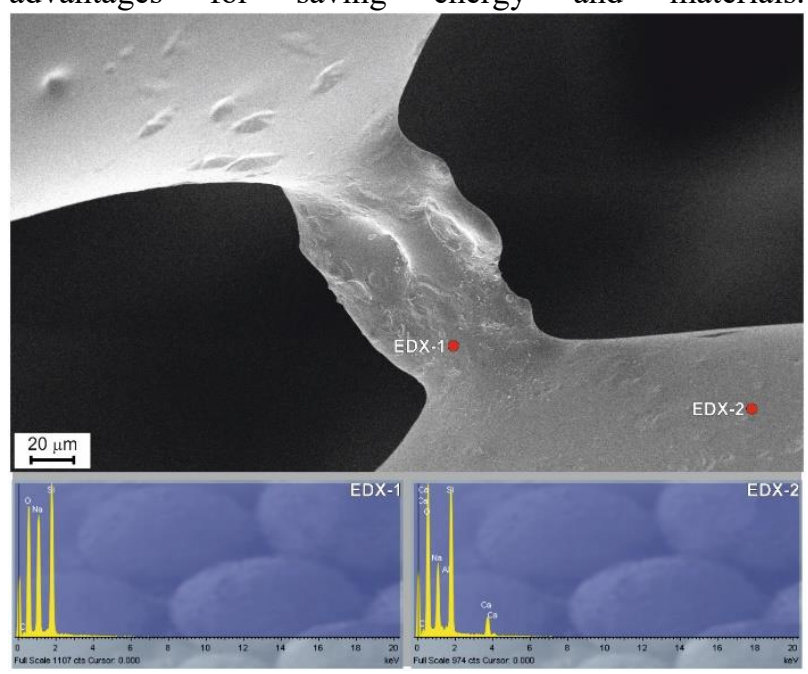

Fig. 10. SEM image highlighting a perfect adhesion between water glass binder and crushed glass aggregates. De-vitrification cores in glass aggregates are observed. Analysis EDX aggregates (EDX-1) and binder (EDX-2).

Obtaining compounds compacted at low temperature $\left(40{ }^{\circ} \mathrm{C} / 24 \mathrm{~h}\right)$ has great advantages to produce materials of great usefulness and durability. The savings in technical processes and materials is very high, and can be treated and machined with warranty from 24 hours of its preparation.

These materials constitute a true substitute for expensive processes, such as the preparation of hot glass. These new products improve technical properties and ease of use that are organic polymers (e. g. epoxy or polyester). The products mechanically finished with this technique can be completed through further compaction with heating to temperatures close to $500{ }^{\circ} \mathrm{C}$.

On the other hand, to produce manufactured with higher compaction the technique of heating at $700{ }^{\circ} \mathrm{C}$ is very convenient, due to the products do not experience excessive deformation and volumetric variations, although the economic cost in resources and energy is much greater.

It is possible to obtain good mechanical results and compacting surface very similar to those defined in this study using lower temperature. Thermal ranges from 550 ${ }^{\circ} \mathrm{C}$ to $600{ }^{\circ} \mathrm{C}$, could be enough for proper compaction of these manufactured products and minor times of exposure to heat, will minimize the overall costs. Linear deformations and changes in the volume of the objects would also be reduced.

\section{References}

1. J.L. Provis and J.S.J. van Deventer, (eds), Geopolymers: Structures, Processing, Properties 
and Industrial Applications, Woodhead Publishing, Cambridge (2009).

2. J.S.J. van Deventer, J.L. Provis and P. Duxson. Min. Engi. 29, 89 (2012).

3. Turner, L. Turner and F. Collins. Const. \& Build. Mat 43, 125 (2013).

4. Villegas, M. A. Duran Suarez, J. A. Fernandez Navarro, J. M. and Sorroche Cruz, A. The glass sculpture. Ed. University of Granada (2017), 350 p. 